Cordeira J. M., M. M. Neureuter, and L. D. Kelleher, 2018: Atmospheric rivers and National Weather Service watches, warnings, and advisories issued over California 2007-2016. J. Operational Meteor., 6 (8), 87-94, doi: https://doi.org/10.15191/nwajom.2018.0608

Journal of Operational Meteorolog. Short Contribution

\title{
Atmospheric Rivers and National Weather Service Watches, Warnings, and Advisories Issued Over California 2007-2016
}

\author{
JASON M. CORDEIRA \\ Plymouth State University, Plymouth, New Hampshire \\ MOLLY M. NEUREUTER \\ Hobart and William Smith Colleges, Geneva, New York \\ LIAM D. KELLEHER \\ Lyndon State College, Lyndonville, Vermont
}

(Manuscript received 26 July 2018; review completed 12 October 2018)

\begin{abstract}
Atmospheric rivers (ARs) are a focus of many global hydrometeorological studies and applications. The impacts of ARs along the United States' West Coast include extreme orographic precipitation that often leads to flooding, flash flooding, debris flows, and other hydrological hazards that necessitate issuance of watches, warnings, and advisories (WWAs) by the National Weather Service (NWS). The objectives of this paper are to quantify and illustrate the relationship between landfalling ARs and high-impact weather events in California by comparing a catalog of landfalling ARs to a 10-year geospatial catalog of WWAs issued by the NWS.

NWS WWAs are issued frequently over California in regions of topography (e.g., the northern Sierra Nevada and Transverse Ranges) in association with flooding and winter weather across northern California and flash flooding across southern California. A large majority of cool-season days with WWAs related to flooding $(\sim 50-$ $75 \%)$ and winter weather ( $\mathbf{6 0}-\mathbf{8 0} \%)$ occur on days with landfalling ARs. Alternatively, landfalling ARs on cool-season days also enhance the likelihood of high-impact weather over different regions of California with greatly increased likelihoods of WWAs relative to climatology as AR intensity increases.
\end{abstract}

\section{Introduction}

Atmospheric rivers (ARs) have emerged as a focus of many global hydrometeorological studies and applications (Ralph et al. 2017). These corridors of enhanced integrated water vapor (IWV) and IWV transport (IVT) accompany landfalling Pacific winter storms in the western United States (among other worldwide locations; American Meteorological Society 2017). Often, ARs are linked to meteorological events that can produce societal impacts from extreme precipitation (e.g., Ralph et al. 2010; Lamjiri et al. 2017), extreme winds (Waliser and Guan 2017), avalanches (Hatchett et al. 2017), floods (Ralph et al. 2006), flash floods and debris flows (Oakley et al. 2017; Young et al. 2017), and shallow landslides (Oakley et al. 2018).
A recent example of the concurrence of a landfalling AR and high-impact weather in California occurred on 20-23 March 2018. During this period, a corridor of enhanced IWV $>40 \mathrm{~mm}$ and IVT magnitudes $>750 \mathrm{~kg}$ $\mathrm{m}^{-1} \mathrm{~s}^{-1}$ along an AR in the warm sector of an extratropical cyclone over the northeast Pacific (Figs. 1a, b) produced regions of 72-h precipitation totals $>200 \mathrm{~mm}$ at locations south of Big Sur and over the northern Sierra Nevada in California (not shown). This landfalling AR resulted in the issuance of hundreds of National Weather Service (NWS) Watches, Warnings, and Advisories (WWAs) for high-impact weather in California related to winter storms, floods, severe weather, and wind over the fourday period, including $>100$ WWAs valid during 22 March 2018 (Fig. 1c).

The primary objectives of this study are to quantify 


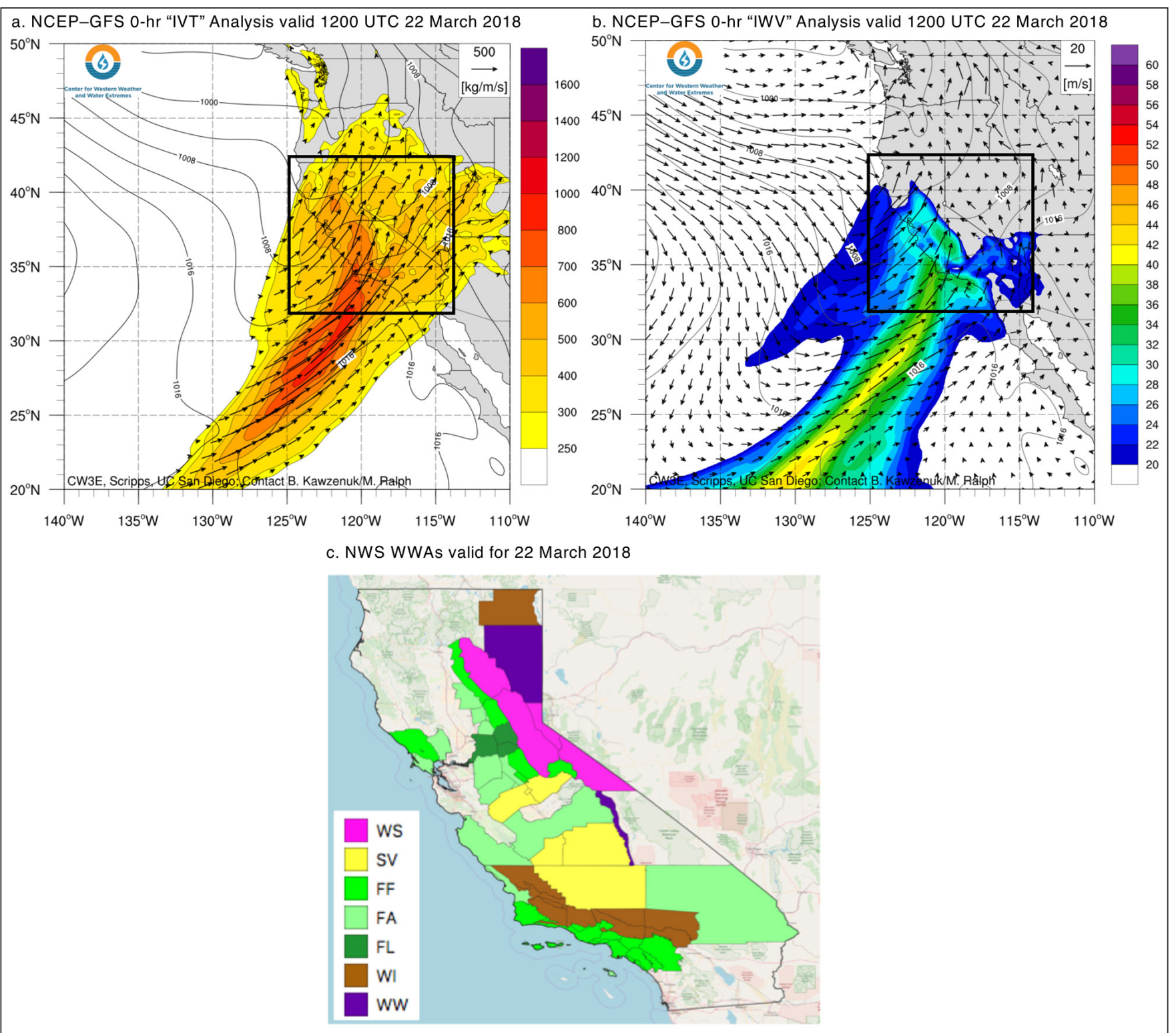

Figure 1. Analyses of (a) IVT magnitude $\left(\mathrm{kg} \mathrm{m}^{-1} \mathrm{~s}^{-1}\right.$; shaded according to scale), direction (vectors scaled according to reference vector and potted for magnitudes $>250 \mathrm{~kg} \mathrm{~m}^{-1} \mathrm{~s}^{-1}$ ), and sea-level pressure (hPa; contours); (b) IWV (mm; shaded according to scale), 850-hPa wind (vectors scaled according to reference vector), and sea-level pressure (hPa; contours); and (c) NWS WWAs for winter storm (WS), severe (SV), flash flood (FF), areal flood (FA), flood (FL), wind (WI), and winter weather (WW) valid on 22 March 2018. Panels (a) and (b) obtained from the Center for Western Weather and Water Extremes at the University of California San Diego Scripps Institution of Oceanography and panel (c) created in QGIS version 2.18.13 using data provided by the University Iowa Environmental Mesonet archive. Click image for an external version; this applies to all figures and tables hereafter.

and illustrate the relationship between landfalling ARs and the potential for high-impact weather events in California by comparing a catalog of landfalling ARs to a 10-year geospatial catalog of WWAs issued by the NWS. This relationship is explored temporally and spatially via two goals: (1) Assess the propensity for a WWA to occur on the same day as a landfalling AR and
(2) Assess the propensity for a landfalling AR to occur on the same day as a WWA.

\section{Data and methods}

This study focuses on WWAs issued by the NWS over California for a 10-calendar-year period between 
1 January 2007 and 31 December 2016. The WWAs are obtained from the Iowa State University Iowa Environmental Mesonet archive (mesonet.agron. iastate.edu/request/gis/watchwarn.phtml) for 10 county warning areas (CWAs) that cover California and are overseen by the Monterey (MTR), Sacramento (STO), Eureka (EKA), Reno (REV), Medford (MFR), Phoenix (PSR), San Diego (SGX), Los Angeles (LOX), Las Vegas (VEF), and Hanford (HNX) NWS weather forecast offices (WFOs; Fig. 2). The former five WFOs are referred to as northern California (NCA) WFOs whereas the latter five WFOs are referred to as southern California (SCA) WFOs, similar to the methods of Young et al. (2017). The WWAs issued across all 10 WFO CWAs (which cover an area larger than the state of California) are clipped to the geometry of California and assigned to NWS Public Forecast Zones (i.e., an NWS-designated geographic region within a CWA) using ESRI ArcMap 10.3.1. Most WWAs are already assigned a Public Forecast Zone; however, some WWAs are issued for Public Forecast Zones that have since merged or been dissolved, and some WWAs are issued as storm-relative polygons (e.g., flash flood, tornado). These WWAs are assigned to a current Public Forecast Zone if their geographic areas overlap by $\geq 100 \mathrm{~km}^{2}$ using the ESRI NAD83 California 0403 projection; a large polygon WWA can therefore impact multiple Public Forecast Zones. Finally, a "WWA catalog" is created from both new ("NEW") or upgraded ("UPG") WWAs and their event beginning date for eight precipitationand hydrologic-related phenomena types typically associated with landfalling ARs: flash floods, floods, areal floods, coastal floods, snow, blizzards, winter storms, and winter weather. The former four phenomena are referred to as "liquid" WWAs, whereas the latter four phenomena are referred to as "frozen" WWAs. Definitions for each of the WWA types can be accessed through the NWS Reference Guide (NWS 2011). Note that the criteria associated with the issuance of a WWA, especially for issuance of precipitation-derived WWAs (e.g., winter storms and winter weather) do vary across Public Forecast Zones based on local climatology.

The WWA catalog is compared to an "AR catalog" that is constructed from days with landfalling ARs produced by Rutz et al. (2014). The AR catalog identifies ARs as locations with IVT magnitudes $\geq 250 \mathrm{~kg} \mathrm{~m}^{-1} \mathrm{~s}^{-1}$ that are $\geq 2,000 \mathrm{~km}$ in length every three hours for 1980-2017 using the National Aeronautical and Space Administration (NASA) Modern-Era Retrospective Analysis for Research and Applications, Version 2
(MERRA-2) Reanalysis dataset on a global $0.5^{\circ}$ latitude $\times 0.625^{\circ}$ longitude resolution grid (Rienecker et al. 2011). A landfalling AR day in this study is defined if any of the three-hour times on a given UTC calendar day satisfy the IVT magnitude and length criteria mentioned above. The grid points from the AR catalog used in this study span every $1^{\circ}$ latitude between $42^{\circ} \mathrm{N}$ and $32^{\circ} \mathrm{N}$ at locations that lie immediately to the west of the California coast (Fig. 2).

Concurrence of WWAs and landfalling ARs is quantified based on whether they overlap in time and space. This relationship is explored both from a "WWA perspective" and from an "AR perspective." The WWA perspective identifies what fraction of WWA days occur concurrently with an AR day, whereas the AR perspective identifies what fraction of AR days occur concurrently with a WWA day. This identification is performed over California, NCA, or SCA, whereby WWAs over each respective region are compared to landfalling ARs at any of the 11 coastal locations, the six northern coastal locations, or the six southern coastal locations, respectively. Note that the aforementioned six locations overlap the central latitude and longitude location

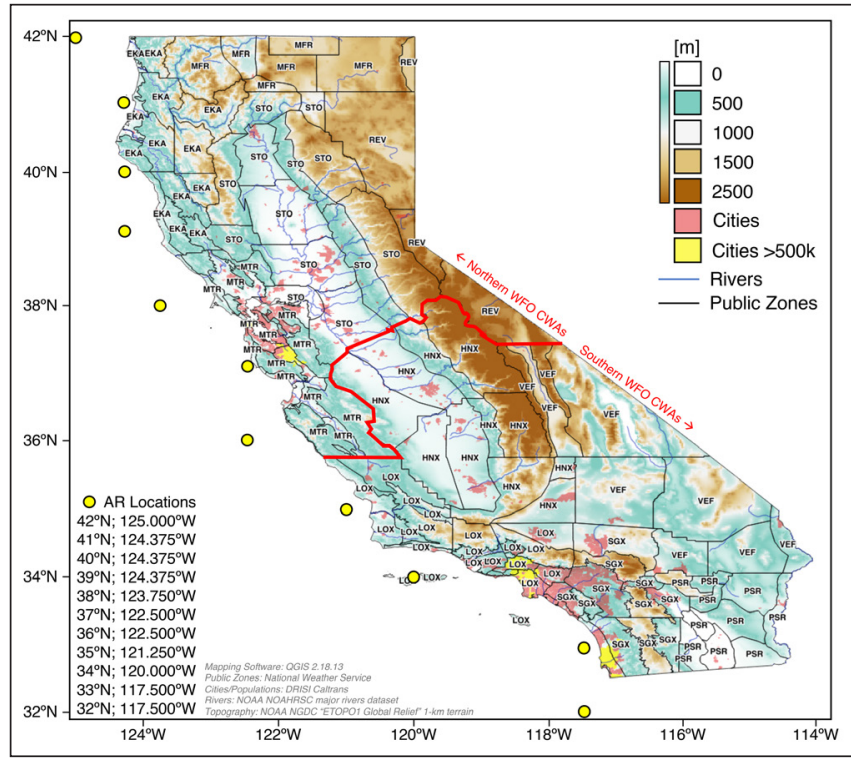

Figure 2. Map of NWS Public Zone boundaries over CA labeled with their parent WFO CWA with $1-\mathrm{km}$ terrain ( $\mathrm{m}$; shaded according to scale). The delineation between northern and southern CA WFO CWAs used in this study is indicated by thick red line. Yellow circles indicate locations used to create the AR catalog discussed in the text. Software and data sources are provided on the image. 
Table 1. Number of WWAs by phenomenon type over California (CA), northern CA, and southern CA for 2007-2016.

\begin{tabular}{|l|l|l|l|l|l|}
\hline & Phenomenon & ID & CA & Northern CA & Southern CA \\
\hline 1 & Flood & FL & 20 & 168 & 30 \\
\hline 2 & Coastal Flood & CF & 227 & 112 & 115 \\
\hline 3 & Flash Flood & FF & 7308 & 830 & 6478 \\
\hline 4 & Areal Flood & FA & 18790 & 6325 & 12465 \\
\hline 5 & Winter Storm & WS & 9146 & 5870 & 3276 \\
\hline 6 & Blizzard & BZ & 4 & 4 & 0 \\
\hline 7 & Winter Weather & WW & 1060 & 696 & 364 \\
\hline $\mathbf{8}$ & Snow & SN & 144 & 114 & 30 \\
\hline $\mathbf{1 - 4}$ & Liquid & & 26345 & 7435 & 19088 \\
\hline $\mathbf{5}-\mathbf{8}$ & Frozen & & 10354 & 14119 & 3670 \\
\hline $\mathbf{1 - 8}$ & All & 36699 & & 22758 \\
\hline
\end{tabular}

\section{Analysis}

\section{a. WWA statistics}

The results in this section focus on 36877 WWAs on 809 unique days associated with the eight liquid or frozen WWAs (Table 1). A large majority (71\%) of the WWAs occurred in association with a flash flood or areal flood, and a minority (28\%) of the WWAs occurred in association with a winter storm or winter weather. The northern five WFOs issued 14119 WWAs on 506 unique days and the southern five WFOs issued 22758 WWAs on 655 unique days. Note that the total of the two regions is $>809$ days because they have overlapping days. Also, the use of "number of WWAs" includes double-counting particular hazards if a watch was issued initially and subsequently upgraded to a warning, whereas the use of "WWA days" only considers whether or not at least one hazard was headlined (i.e., issued at least one WWA). Northern WFOs issued $82 \%$ more frozen WWAs as compared to southern WFOs, whereas southern WFOs issued 157\% more liquid WWAs as compared to northern WFOs. The latter occurred primarily in association with the 18 943 WWAs issued for flash floods and areal floods.

The aforementioned statistics suggest that a majority of WWAs in SCA are issued in association with rain events, whereas a majority of WWAs in NCA are issued in association with snow or winter storm events. The majority of liquid, rain-related WWAs occurred over SCA primarily during July-September (Fig. 3a) with a maximum frequency $>45-60 \mathrm{yr}^{-1}$ over NWS Public Forecast Zones encompassing the Transverse Ranges and desert regions (Fig. 3b). Secondary maxima in liquid WWAs occurred over central-coastal California with a frequency of 20-30 $\mathrm{yr}^{-1}$ over NWS Public Forecast Zones encompassing the coastal ranges. Alternatively, the majority of the frozen, snow-related WWAs occurred over NCA primarily during December-March (Fig. 3a) with a maximum frequency $>40-55 \mathrm{yr}^{-1}$ over NWS Public Forecast Zones encompassing the higher terrain of the northern Sierra Nevada, Mt. Shasta, and Trinity Alps region (Fig. 3c). Comparatively few WWAs occur over NCA or SCA during April-June (Fig. 3a).

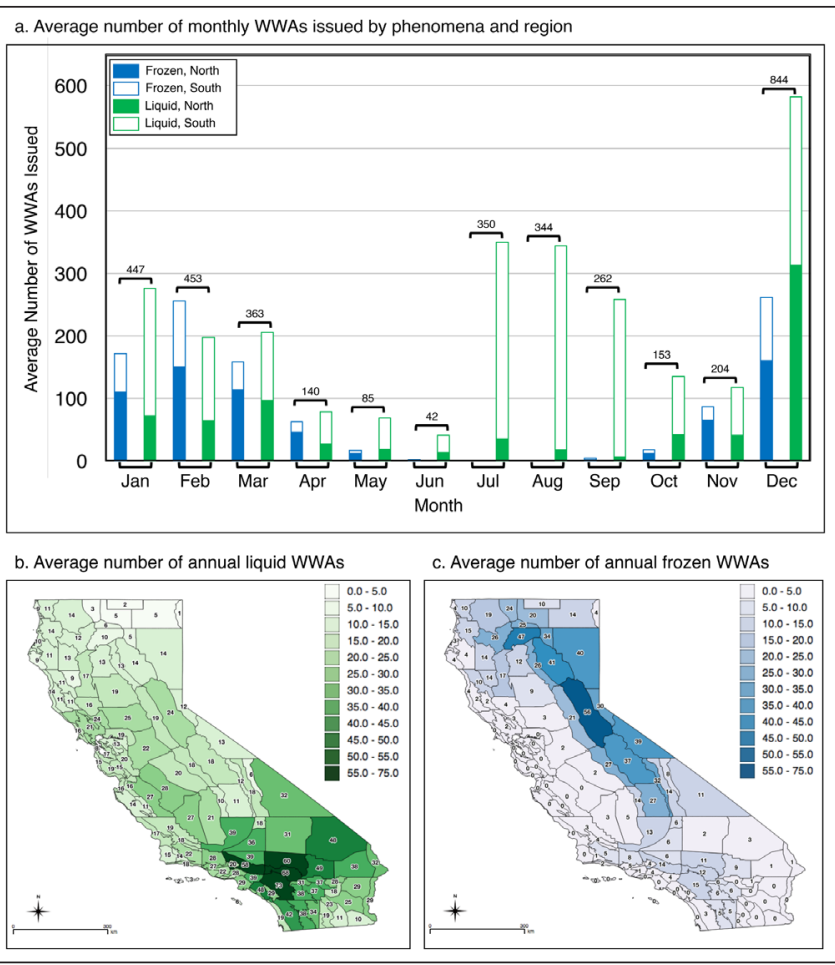

Figure 3. (a) Average monthly number of frozen (blue) and liquid (green) WWAs issued over northern CA (solid fill) and southern CA (clear fill). The total for both regions and phenomena is given above each set of stacked bars; (b) and (c) average number of annual liquid and frozen WWAs by NWS Public Forecast Zone, respectively. 


\section{b. WWAs associated with landfalling ARs}

The 809, 506, and 655 unique WWA days over California, NCA, and SCA, respectively, overlapped with 363, 281, and 181 AR days. The seasonality of these concurrent WWA-AR days partitioned for liquid and frozen phenomena are shown in Fig. 4. The largest fraction of WWA-AR days for combined liquid and frozen WWAs occurred predominantly during the coolseason months of October to March over California (270 of $404 ; 67 \%$ ), over NCA (234 of 323; 72\%), and over SCA (142 of 308; 46\%). The fractions of WWAAR days during the warm season months of April to September over California (93 of 405; 23\%), NCA (47 of $183 ; 26 \%$ ), and SCA (39 of $347 ; 11 \%$ ) are noticeably smaller when landfalling ARs are less frequent (Neiman et al. 2008)

The October-March cool season contained 404, $324,223,149$, and 70 days when there were $\geq 1$, $\geq 10, \geq 25, \geq 50$, and $\geq 100$ individual WWAs issued or upgraded across CA, respectively. These potentially increasingly "higher impact" WWA days (e.g., those with widespread or numerous hazards) are all associated with an increasing likelihood of an overlap with a landfalling AR day (Table 2). The fraction of cool-season WWA-AR days increases from $67 \%$ for days with $\geq 1$ WWA over California to $84 \%$ for days with $\geq 100$ WWAs over California. Similar increases in the fraction of cool-season WWA-AR days from $72 \%$ to $88 \%$ and from $46 \%$ to $81 \%$ are observed regionally

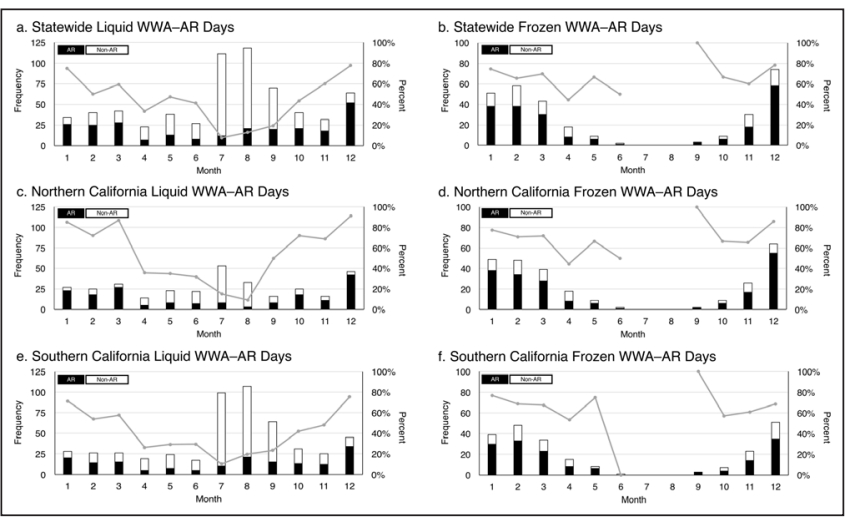

Figure 4. Number of unique liquid (left panels) and frozen (right panels) WWA days (total height of white columns) over $(\mathrm{a}-\mathrm{b}) \mathrm{CA},(\mathrm{c}-\mathrm{d})$ northern $\mathrm{CA}$, and $(\mathrm{e}-\mathrm{f})$ southern CA occurring concurrently on a day with a landfalling AR (height of the black columns filling the white columns) by month of the year. The percentage of concurrent WWA-AR days is indicated by the gray line. over NCA and SCA, respectively (not shown). These results suggest that such high-impact, cool-season WWA days are far more likely to occur in association with a landfalling AR across California than not.

\section{c. Cool-season landfalling ARs of different intensity and WWAs}

The AR catalog contained 847 unique OctoberMarch cool-season, landfalling AR days over California (i.e., at any of the 11 coastal latitudes). These can be partitioned into 824 unique landfalling AR days over NCA (i.e., inclusive of the six northern coastal latitudes) and 323 unique landfalling AR days over SCA (i.e., inclusive of the six southern coastal latitudes). These landfalling AR days are classified by daily maximum IVT magnitude and compared to the likelihood of at least one WWA across California, NCA, and SCA (Fig. 5). Whereas landfalling ARs of at least minimal intensity (e.g., IVT magnitude $\geq 250 \mathrm{~kg} \mathrm{~m}^{-1} \mathrm{~s}^{-1}$ ) are associated with WWAs $\sim 50 \%$ of the time for California and NCA, they are associated with WWAs $>65 \%$ of the time for SCA. These likelihoods appear to reflect the variability of AR intensities as a function of latitude along the United States' West Coast (Rutz et al. 2014). In other words, an IVT magnitude $\geq 250 \mathrm{~kg} \mathrm{~m}^{-1} \mathrm{~s}^{-1}$ is far more uncommon over SCA than over NCA and is more likely to be associated with a WWA. As such, landfalling ARs with maximum IVT magnitudes $\geq 500 \mathrm{~kg} \mathrm{~m}^{-1} \mathrm{~s}^{-1}$ and $\geq 750 \mathrm{~kg} \mathrm{~m}^{-1} \mathrm{~s}^{-1}$ are associated with WWAs $\sim 60-65 \%$ and $\sim 70-75 \%$ of the time over California and NCA, respectively, and $>75-80 \%$ over SCA. Landfalling ARs with maximum IVT magnitudes $\geq 900 \mathrm{~kg} \mathrm{~m}^{-1} \mathrm{~s}^{-1}$ appear to be associated with WWAs $\sim 80-90 \%$ of the time, irrespective of location.

The AR catalog contained 597 and 136 unique October-March cool-season, landfalling AR days at $38^{\circ} \mathrm{N}$ for $\mathrm{NCA}$ that featured a daily maximum IVT magnitude $\geq 250 \mathrm{~kg} \mathrm{~m}^{-1} \mathrm{~s}^{-1}$ and $\geq 500 \mathrm{~kg} \mathrm{~m}^{-1} \mathrm{~s}^{-1}$, respectively. The likelihood of at least one WWA on days with landfalling ARs at $38^{\circ} \mathrm{N}$ with a daily maximum IVT magnitude $\geq 250 \mathrm{~kg} \mathrm{~m}^{-1} \mathrm{~s}^{-1}$ is $20-25 \%$ within Public Forecast Zones across the northern Sierra Nevada and 5-10\% within Public Forecast Zones across the coastal ranges and Central Valley (Fig. 6a). These likelihoods increase to $40-45 \%$ and $15-20 \%$, respectively, for landfalling ARs at $38^{\circ} \mathrm{N}$ with a daily maximum IVT magnitude $\geq 500 \mathrm{~kg} \mathrm{~m}^{-1} \mathrm{~s}^{-1}$ (Fig. 6b). The difference between these likelihoods and the likelihood that any given Public Forecast Zone contains at least 
Table 2. Fraction of landfalling AR days that feature different numbers of WWAs over California by month, October-March cool season ("Cool"), April-September warm season ("Warm"), and by year ("All").

\begin{tabular}{|c|c|c|c|c|c|c|c|c|c|c|c|c|c|c|c|}
\hline WWAs & Jan & Feb & Mar & Apr & May & Jun & Jul & Aug & Sep & Oct & Nov & Dec & Cool & Warm & All \\
\hline$\geq 1$ & $74 \%$ & $61 \%$ & $66 \%$ & $38 \%$ & $39 \%$ & $32 \%$ & $11 \%$ & $18 \%$ & $31 \%$ & $54 \%$ & $58 \%$ & $78 \%$ & $67 \%$ & $23 \%$ & $45 \%$ \\
\hline$\geq 10$ & $80 \%$ & $60 \%$ & $71 \%$ & $38 \%$ & $35 \%$ & $31 \%$ & $15 \%$ & $17 \%$ & $26 \%$ & $45 \%$ & $66 \%$ & $81 \%$ & $70 \%$ & $23 \%$ & $50 \%$ \\
\hline$\geq 25$ & $84 \%$ & $66 \%$ & $77 \%$ & $47 \%$ & $44 \%$ & $60 \%$ & $19 \%$ & $23 \%$ & $24 \%$ & $48 \%$ & $57 \%$ & $83 \%$ & $73 \%$ & $28 \%$ & $56 \%$ \\
\hline$\geq 50$ & $81 \%$ & $67 \%$ & $84 \%$ & $44 \%$ & $40 \%$ & N/A & $25 \%$ & $30 \%$ & $27 \%$ & $38 \%$ & $77 \%$ & $83 \%$ & $75 \%$ & $30 \%$ & $61 \%$ \\
\hline$\geq 100$ & $76 \%$ & $90 \%$ & $89 \%$ & $20 \%$ & N/A & N/A & $40 \%$ & $14 \%$ & $33 \%$ & N/A & $86 \%$ & $88 \%$ & $84 \%$ & $28 \%$ & $67 \%$ \\
\hline
\end{tabular}

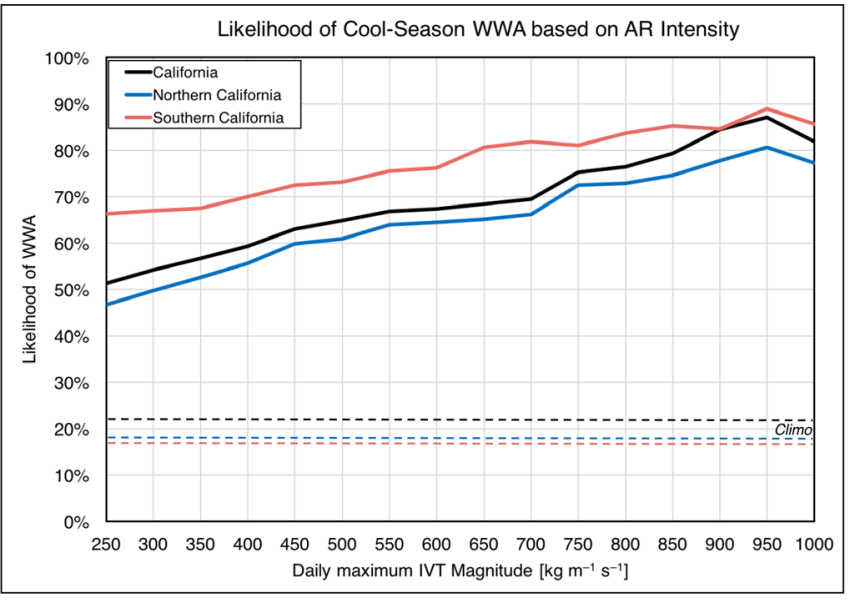

Figure 5. Likelihood of at least one WWA within one NWS Public Zone anywhere in CA, northern CA, or southern CA during the October-March cool season as a function of maximum daily IVT magnitude associated with a landfalling AR. The October-March climatological values (i.e., likelihood that any given day contains at least one WWA) are indicated as dashed lines for reference.

one WWA on any given day (i.e., climatology) are illustrated in Figs. 6c-d. The likelihood of at least one WWA on days with landfalling ARs at $38^{\circ} \mathrm{N}$ is generally 5-15 percentage points higher (e.g., 26\% as compared to $11 \%$ ) than climatology for daily maximum IVT magnitudes $\geq 250 \mathrm{~kg} \mathrm{~m}^{-1} \mathrm{~s}^{-1}$ (Fig. 6c). The likelihood is 15-35 percentage points higher than climatology for daily maximum IVT magnitudes $\geq 500 \mathrm{~kg} \mathrm{~m}^{-1} \mathrm{~s}^{-1}$ (Fig. $6 \mathrm{~d})$. These results suggest that landfalling ARs with IVT magnitudes of $250-500 \mathrm{~kg} \mathrm{~m}^{-1} \mathrm{~s}^{-1}$ can double or triple the odds of high-impact weather (i.e., associated with at least one WWA) across Public Forecast Zones in northern and central California as compared to climatology.

A corresponding analysis at $33^{\circ} \mathrm{N}$ for SCA contained 223 and 28 unique October-March coolseason, landfalling AR days that featured a daily maximum IVT magnitude $\geq 250 \mathrm{~kg} \mathrm{~m}^{-1} \mathrm{~s}^{-1}$ and $\geq 500$ $\mathrm{kg} \mathrm{m}^{-1} \mathrm{~s}^{-1}$, respectively. The likelihood of at least one

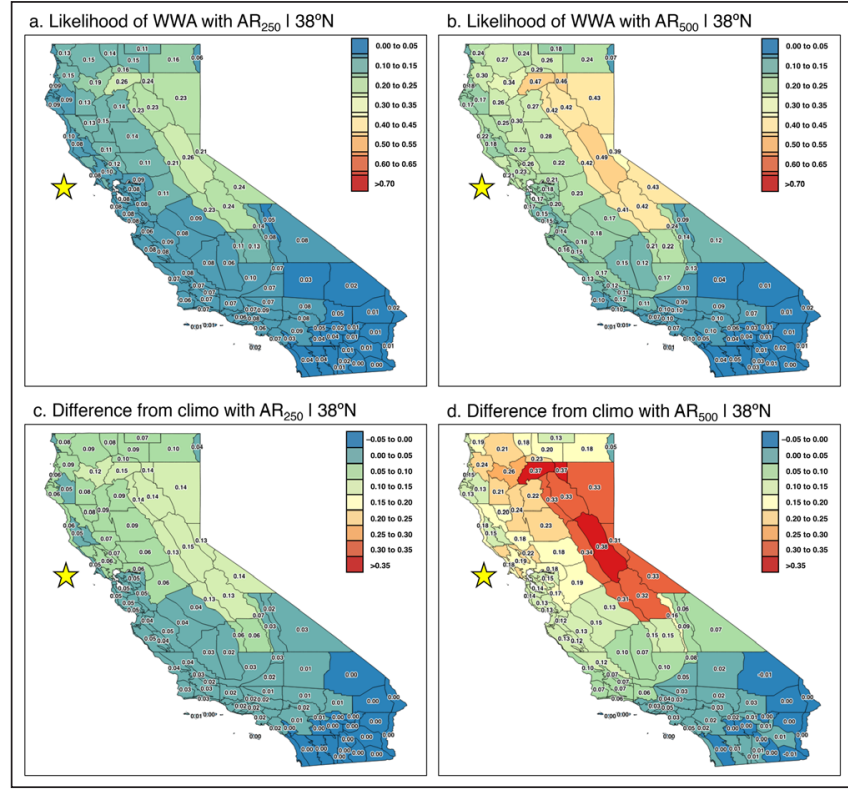

Figure 6. Likelihood of at least one WWA at each Public Forecast Zone in CA on days with a landfalling $\mathrm{AR}$ at $38^{\circ} \mathrm{N}$ with a maximum daily intensity (a) $\geq 250$ $\mathrm{kg} \mathrm{m}^{-1} \mathrm{~s}^{-1}$ and (b) $\geq 500 \mathrm{~kg} \mathrm{~m}^{-1} \mathrm{~s}^{-1}$ during October-March and their respective differences from climatology in (c) and (d). Climatology is calculated based on random chance over the 10-year period.

WWA on days with landfalling ARs at $33^{\circ} \mathrm{N}$ with a daily maximum IVT magnitude $\geq 250 \mathrm{~kg} \mathrm{~m}^{-1} \mathrm{~s}^{-1}$ is 20 $35 \%$ within Public Forecast Zones across the southern coastal Transverse Ranges and 25-35\% within Public Forecast Zones across the Sierra Nevada (Fig. 7a). These likelihoods increase to $>50-70 \%$ for landfalling ARs at $33^{\circ} \mathrm{N}$ with a daily maximum IVT magnitude $\geq 500 \mathrm{~kg}$ $\mathrm{m}^{-1} \mathrm{~s}^{-1}$ (Fig. 7b). The likelihood of at least one WWA on days with landfalling ARs at $33^{\circ} \mathrm{N}$ is $20-30$ percentage points higher (e.g., 36\% as compared to $16 \%$ ) than climatology for daily maximum IVT magnitudes $\geq 250$ $\mathrm{kg} \mathrm{m}^{-1} \mathrm{~s}^{-1}$ (Fig. 7c). It is 40-60 percentage points higher than climatology for daily maximum IVT magnitudes $\geq 500 \mathrm{~kg} \mathrm{~m}^{-1} \mathrm{~s}^{-1}$ (Fig. 7d). These results suggest that landfalling ARs with intensities of $250-500 \mathrm{~kg} \mathrm{~m}^{-1} \mathrm{~s}^{-1}$ can triple or quadruple the odds of high-impact weather 


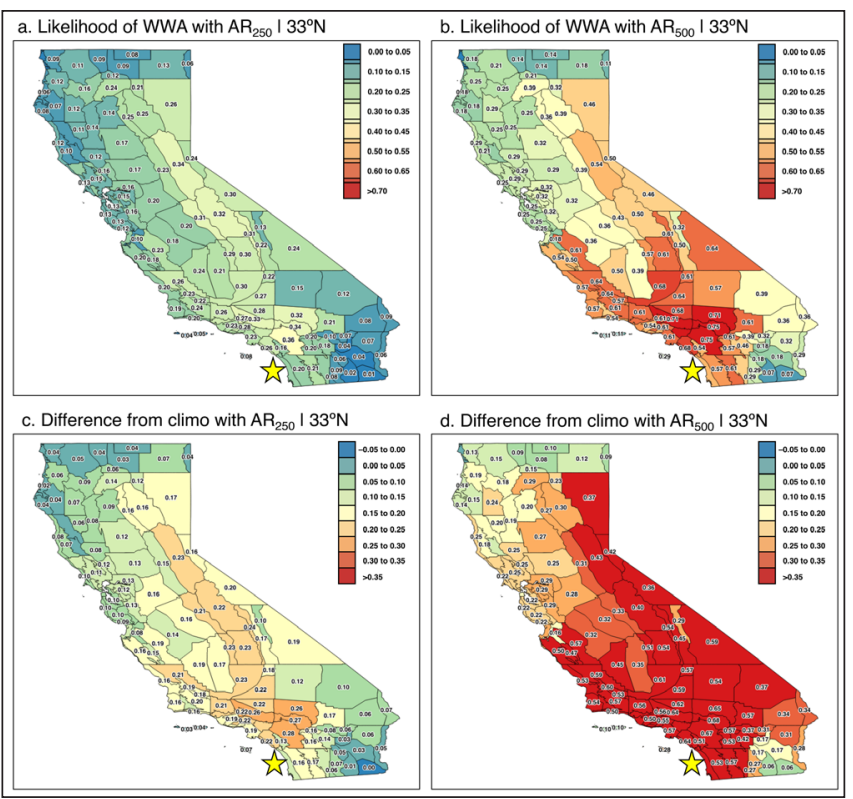

Figure 7. As in Fig. 5, except for landfalling ARs at $33^{\circ} \mathrm{N}$.

(i.e., associated with at least one WWA) across Public Forecast Zones in central and southern California as compared to climatology.

\section{Discussion}

The propensity for high-impact weather defined by NWS WWAs on days with landfalling ARs (e.g., 50$65 \%$; Fig. 5) presented in this study agree with those of past studies of AR-related hazards. For example, landfalling ARs are associated with $\sim 40-75 \%$ of extreme wind and precipitation events over $40 \%$ of the world's coastlines (Waliser and Guan 2017), 31-65\% of coastal western United States avalanche fatalities (Hatchet et al. 2017), $64 \%$ of high-impact hydrological events (i.e., floods, flash floods, or debris flows) over northern California (Young et al. 2017), 60-90\% of extreme precipitation events (Oakley et al. 2018) known to produce shallow landslides, and $76-82 \%$ of San Francisco Bay Area landslides (Cordeira et al. 2018). Future work is required to (1) apply these results to possible forecasting applications that may provide enhanced situational awareness and (2) investigate verification of these WWAs. For example, forecasts of IVT magnitudes at different latitudes along the West Coast and statistics derived from this (or similar, future) studies could be combined in real time to identify the historic likelihood of high-impact weather events (i.e., WWAs) over NWS Public Forecast Zones across the western United States and how likely they are to verify. Similarly, results presented on the propensity for high-impact weather on days with landfalling ARs in this study aggregated WWAs. Future work could subdivide these aggregated WWAs into individual hazards mentioned in this paper or additional hazards not mentioned in this paper (e.g., high winds). Such an analysis and application to forecasting might resemble the NWS "Experimental Enhanced Hazardous Weather Outlook" (nws.weather.gov/products/PDD/SGF \%20 EHWO PDD final.pdf), which displays qualitative risk (e.g., "limited," "elevated," "significant," "extreme") as a function of forecast time of hazardous weather (e.g., excessive heat, flooding, lightning) derived from quantitative thresholds of meteorological parameters.

\section{Conclusions}

The twin goals of this study sought to temporally and spatially assess the propensity for WWAs (i.e., highimpact weather) over California to occur on the same day as a landfalling AR and vice versa. A climatology of WWAs over 10 years demonstrated that a majority of WWAs in SCA are issued in association with rain events during the warm season, whereas a majority of WWAs in NCA are issued in association with snow events during the October-March cool season, with frequencies of 45-60 $\mathrm{yr}^{-1}$ over NWS Public Forecast Zones with notable topography (e.g., the northern Sierra Nevada in NCA and the Transverse Ranges in SCA; Figs. 2 and 3). The fraction of cool-season WWA days with at least one WWA in both NCA and SCA that occur on the same day as a landfalling AR is $72 \%$ and $46 \%$, respectively, whereas the fraction of April-September warm-season WWAs days with at least one WWA that occur on the same day as a landfalling AR is $\leq 25 \%$ (Fig. 4). The fraction of high-impact, cool-season WWA days that occur on the same day as a landfalling AR increases from $72 \%$ to $88 \%$ over NCA and from $46 \%$ to $81 \%$ over SCA as the number of WWAs needed to qualify as a WWA increases (Table 2). These results collectively suggest that higher-impact, cool-season WWA days are far more likely to occur in association with a landfalling ARs across California than not.

The fraction of cool-season landfalling ARs with IVT magnitudes $\geq 250 \mathrm{~kg} \mathrm{~m}^{-1} \mathrm{~s}^{-1}$ that are associated with at least one WWA was $\sim 50 \%$ over NCA and $\sim 65 \%$ over SCA (Fig. 5). These fractions increase quasi-linearly to $>75 \%$ over both regions associated with landfalling ARs with IVT magnitudes that increase to $\geq 750 \mathrm{~kg} \mathrm{~m}^{-1} \mathrm{~s}^{-1}$. Cool-season landfalling ARs with IVT magnitudes 
$\geq 250 \mathrm{~kg} \mathrm{~m}^{-1} \mathrm{~s}^{-1}$ over the 10 -year study period at $38^{\circ} \mathrm{N}$ generated $\sim 20-25 \%$ likelihoods of at least one WWA in Public Forecast Zones across the northern Sierra Nevada and coastal ranges, increasing to $\sim 40-45 \%$ for landfalling ARs with IVT magnitudes $\geq 500 \mathrm{~kg}$ $\mathrm{m}^{-1} \mathrm{~s}^{-1}$ (Fig. 6). Similarly, landfalling ARs with IVT magnitudes $\geq 250 \mathrm{~kg} \mathrm{~m}^{-1} \mathrm{~s}^{-1}$ over the 10 -year study period at $33^{\circ} \mathrm{N}$ generated $\sim 25-35 \%$ likelihoods of at least one WWA in Public Forecast Zones across the Transverse Ranges, increasing to $>50-75 \%$ for landfalling ARs with IVT magnitudes $\geq 500 \mathrm{~kg} \mathrm{~m}^{-1} \mathrm{~s}^{-1}$ (Fig. 7). These results collectively suggest that landfalling ARs may not always occur in association with high-impact weather over California; however, landfalling ARs with IVT magnitudes $\geq 500-750 \mathrm{~kg} \mathrm{~m}^{-1} \mathrm{~s}^{-1}$, especially over southern California, usually do occur in association with high-impact weather that necessitates a WWA by the NWS.

Acknowledgments: Results of this project originated from two undergraduate research projects completed during summer 2017 at Plymouth State University with support provided by (1) the State of California-Department of Water Resources award \#4600010378 and the United States Army Corps of Engineers award \#W912HZ-15-2-0019, both as part of broader projects led by the University of California San Diego, Scripps Institution of Oceanography's Center for Western Weather and Water Extremes and (2) Plymouth State University. Data used in this study are cited in the references and can be accessed through the methodologies mentioned in the second section of this paper. The authors would like to thank Dr. Amy Villamagna (Plymouth State University) who provided valuable guidance to the authors on many aspects of the geospatial methodologies and analyses presented in this manuscript.

\section{REFERENCES}

American Meteorological Society, 2017: Glossary of Meteorology. [Available online at glossary.ametsoc.org/ wiki/Atmospheric river.]

Cordeira, J. M., J. Stock, M. D. Dettinger, A. Young, J. Kalansky, and F. M. Ralph, 2018: A 142-year climatology of northern California landslides and atmospheric rivers. Bull. Amer. Met. Soc., in review.

Hatchett, B. J., S. Burak, J. J. Rutz, N. S. Oakley, E. H. Bair, and M. L. Kaplan, 2017: Avalanche fatalities during atmospheric river events in the western United States. J. Hydrometeor., 18, 1359-1374, Crossref.
Lamjiri, M. A., M. D. Dettinger, F. M. Ralph, and B. Guan, 2017: Hourly storm characteristics along the U.S. West Coast: Role of atmospheric rivers in extreme precipitation. Geophys. Res. Lett., 44, 7020-7028, Crossref.

Neiman, P. J., F. M. Ralph, G. A. Wick, J. D. Lundquist, and M. D. Dettinger, 2008: Meteorological characteristics and overland precipitation impacts of atmospheric rivers affecting the West Coast of North America based on eight years of SSM/I satellite observations. $J$. Hydrometeor., 9, 22-47, Crossref.

NWS, 2011 National Weather Service Reference Guide. [Available online at www.weather.gov/media/ publications/nws guide/NWS Reference Guide.pdf].

Oakley, N. S., J. T. Lancaster, M. L. Kaplan, and F. M. Ralph, 2017: Synoptic conditions associated with cool-season post-fire debris flows in the Transverse Ranges of southern California. Nat. Hazards, 88, 327-354, Crossref.

B. J. Hatchett, J. Stock, F. M. Ralph, S. Roj, and S. Lukashov, 2018: A 22-year climatology of coolseason hourly precipitation thresholds conducive to shallow landslides in California. Earth Interact., 22, Paper 14, 1-35, Crossref.

Ralph, F. M., P. J. Neiman, G. A. Wick, S. I. Gutman, M. D. Dettinger, D. R. Cayan, and A. B. White, 2006: Flooding on California's Russian River: Role of atmospheric rivers. Geophys. Res. Lett., 33, L13801, 1-5, Crossref.

., E. Sukovich, D. Reynolds, M. Dettinger, S. Weagle, W. Clark, and P. J. Neiman, 2010: Assessment of extreme quantitative precipitation forecasts and development of regional extreme event thresholds using data from HMT-2006 and COOP observers. $J$. Hydrometeor., 11, 1286-1304, Crossref. , and Coauthors, 2017: Atmospheric rivers emerge as a global science and applications focus. Bull. Amer. Met. Soc., 98, 1969-1973, Crossref.

Rienecker, M. M., and Coauthors, 2011: MERRA: NASA's Modern-Era Retrospective Analysis for Research and Applications. J. Climate, 24, 3624-3648, Crossref.

Rutz, J. J., W. J. Steenburgh, and F. M. Ralph, 2014: Climatological characteristics of atmospheric rivers and their inland penetration over the western United States. Mon. Wea. Rev., 142, 905-921, Crossref.

Waliser, D., and B. Guan, 2017: Extreme winds and precipitation during landfall of atmospheric rivers. Nat. Geosci., 10, 179-183. Crossref.

Young, A. M., K. T Skelly, K. T, and J. M. Cordeira, 2017: High-impact hydrologic events and atmospheric rivers in California: An investigation using the NCEI storm events database. Geophys. Res. Lett., 44, 3393-3401, Crossref. 